\title{
Cosandey C., Robinson M., 2000, Hydrologie continentale
}

Armand Colin, Paris, 2000, 368 p.

\section{André Weisrock}

\section{(2) OpenEdition}

\section{Journals}

Édition électronique

URL : http://journals.openedition.org/rge/2715

DOI : $10.4000 /$ rge. 2715

ISSN : 2108-6478

Éditeur

Association des géographes de l'Est

Édition imprimée

Date de publication : 1 septembre 2002

ISSN : 0035-3213

\section{Référence électronique}

André Weisrock, « Cosandey C., Robinson M., 2000, Hydrologie continentale », Revue Géographique de l'Est [En ligne], vol. 42 / 4 | 2002, mis en ligne le 15 décembre 2010, consulté le 24 septembre 2020. URL : http://journals.openedition.org/rge/2715 ; DOI : https://doi.org/10.4000/rge.2715

Ce document a été généré automatiquement le 24 septembre 2020.

Tous droits réservés 


\title{
Cosandey C., Robinson M., 2000, Hydrologie continentale
}

Armand Colin, Paris, 2000, 368 p.

\author{
André Weisrock
}

\section{RÉFÉRENCE}

Cosandey C., Robinson M. - Hydrologie continentale, Armand Colin, Paris, 2000, 368 p.

1 La collection U-Géographie dirigée par Ph. Pinchemel s'enrichit d'un bon traité d'hydrologie continentale destiné aux étudiants et aux praticiens de l'environnement. Son plan procède d'une démarche naturaliste très logique qui prend le cycle de l'eau comme fil conducteur: une première partie sur la phase aérienne du cycle de l'eau (trois chapitres sur les précipitations, les interceptions de celles-ci, l'évaporation et l'évapotranspiration, soit 111 pages), une deuxième partie sur la phase souterraine du cycle de l'eau (deux chapitres sur l'eau du sol et les réserves hydriques, l'eau des nappes et les réserves hydrologiques: 73 pages), une troisième partie sur les transferts à l'échelle des versants et des bassins versants, les processus, les mesures et la modélisation (deux chapitres sur «de l'eau qui tombe à l'eau qui s'écoule : processus des transferts à l'échelle des versants et du bassin versant", et "mesure et modélisation des écoulements ", soit 64 pages). La quatrième partie est consacrée aux conséquences des activités humaines sur le cycle de l'eau, examinant en trois chapitres la gestion des barrages-réservoirs et la modification des écoulements, les conséquences sur le cycle de l'eau des changements d'usages dans l'espace du bassin versant, le rôle hydrologique de la végétation : afforestation, déforestation, en 64 pages.

Ce livre a l'avantage de proposer sous une forme relativement condensée une mise au point très claire des nouveautés acquises depuis une trentaine d'années dans le domaine de l'hydrologie continentale, sans tomber dans l'écueil d'un exposé scientifique trop pointu : on y trouvera rapidement des rappels précis de définitions, de même que les formules les plus essentielles, grâce à un index thématique très utile. 
L'ouvrage fait une part essentielle aux mécanismes et aux dynamiques : il se nourrit en grande partie des résultats de recherches menées par le Laboratoire de Géographie physique Pierre Birot, particulièrement en ce qui concerne les transferst sur les versants et dans les bassins versants, le rôle du couvert forestier, l'influence des activités humaines sur le cycle de l'eau. Les trois premières parties, qui entrent dans le détail des processus naturels, se situent à l'amont de toute préoccupation environnementale et sont de ce fait fondamentales. Il convient de plus de souligner la modestie des auteurs, qui estiment que leur ouvrage est axé sur la zone dite tempérée du globe : ils donnent cependant de multiples exemples qui dépassent largement cette limite. Enfin, bien que les auteurs soient très au fait de la modélisation, ils en soulignent les limites et insistent sur la complexité et la difficulté de mesure des processus initiaux, donnant ainsi encore aux « naturalistes » quelque raison d'espérer. 